\title{
Peaceful Acres
}

\section{By ELIZABETH CRUICKSHANK, Regina}

We have become the proud possessors of a cabin in just the kind of situation we have always longed for: a little meadow bordered on two sides by the heavily treed river, with hills all around.

From a crack in the wood-shed, wrens flit constantly to satisfy the enormous appetites of their noisy quints. Goldfinches fly in a happy mood, taking time out to perform their gay aerial dance as they visit thistle and dandelion and slake their thirst in spoon-size pools of morning dew. Doves croon their mournful dirge to a pair of babies as they wobble around in their loose twig nest. Robins, Clay and Song Sparrows, thrushes and kingbirds share the same tangle, while Meadowlarks in the grass are neighbor to the little Spotted Sandpipers.

Screech Owls do not screech we found out; they gurgle in the early morning, after a successful hunting foray in the farmyard across the river or our meadow, where toads are plentiful. Tree, Barn and Bank Swallows, Kingbirds and Nighthawks do their duty in the mosquito war, but there always seem to be armies left.

From our kitchen window we were thrilled to see a pair of Black-billed Cuckoos gliding gracefully as they captured caterpillars, showing particular fondness for the really fuzzy ones. Their nest looks like a hitand-miss affair, just a platform of twigs where the quill-covered twins seem very early able to take care of their own needs. Great Blue Herons always call for shouts from the children. They fly low as they visit the slough up river. Six Flickers, from a hollow tree near the road, gave us a sight to remember as the whole family dug for ants in a sandy mound by the dyke. Pelicans, ducks and hawks sail the skyways at all hours. Crows fly purposefully or perch to worry the Yellow Warblers or Catbirds who thought they had hidden their precious families from sight.

How very fortunate we are, we think, as we watch the slanting sun glinting on little blonde heads, while the wee girls examine the cradles

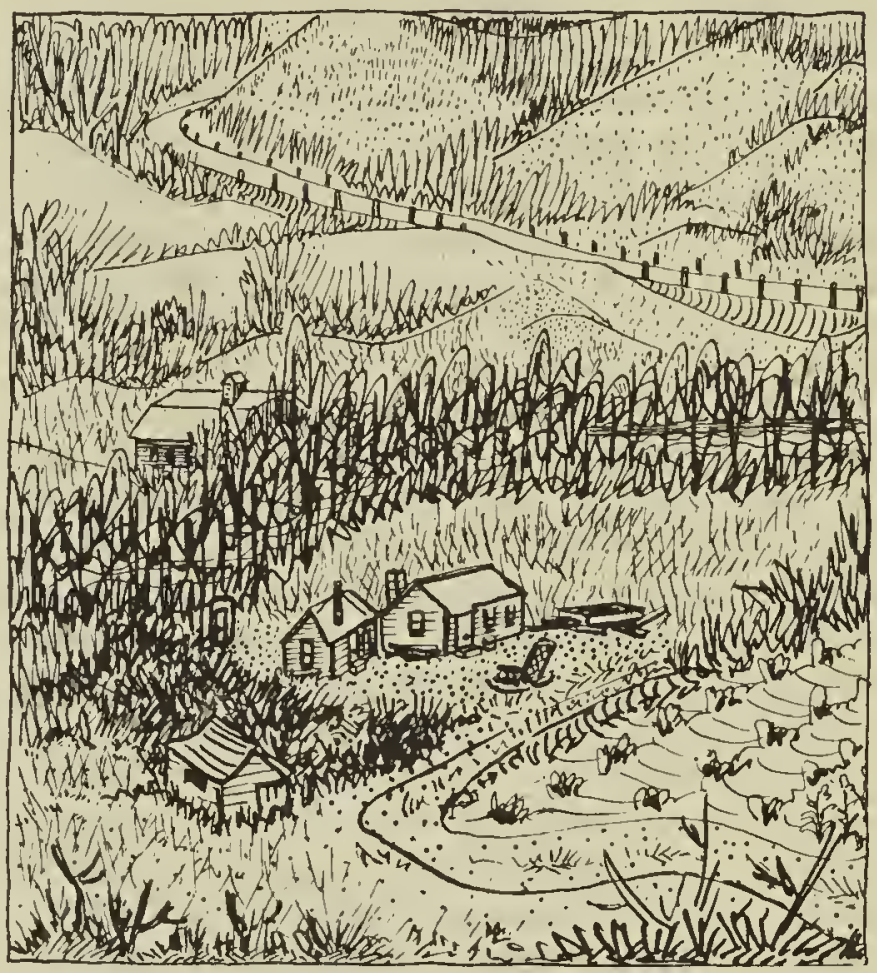

Sketch by $M$. Lawrence PEACEFUL ACRES

in the stinkweed pods where the tiny seeds sleep until they ripen to mahogany red.

Peaceful acres, our very own!

\section{HOW TO REMOVE PORCUPINE QUILLS}

Mr. A. Baltz, Georgetown, B.C., writes that some time ago a fisherman told him that his small dog nearly died after "dequilling." The Blue Jay (Vol. XIII, No. 1) describes an "Adventure with a Porcupine" in which the quills are yanked from the dog with pliers. Neither of these accounts mentioned a fact which allows the quills to be removed without pain. Before using the pliers, cut off the porcupine quills with sharp scissors, leaving only enough quill to be caught by the pliers. When the quill is cut, the air is released, and the barb loses its grip. Then the quill can be pulled out easily.

Back Cover-Mrs. M. E. Robinson's picture of the Mute Swan family on the banks of Wascana Creek in Regina won first prize in the nature photography section at Regina Exhibition. 